\title{
Localization of the Panhypopituitary Dwarf Mutation (df) on Mouse Chromosome 11 in an Intersubspecific Backcross
}

\author{
Marion S. Buckwalter, Ronald W. Katz, and Sally A. Camper' \\ Department of Human Genetics, University of Michigan Medical School, Ann Arbor, Michigan 48109-0618
}

Received November 6, 1990; revised February 2, 1991

\begin{abstract}
Ames dwarf (df) is an autosomal recessive mutation characterized by severe dwarfism and infertility. This mutation provides a mouse model for panhypopituitarism. The dwarf phenotype results from failure in the differentiation of the cells which produce growth hormone, prolactin, and thyroid stimulating hormone. Using the backcross (DF/B$d f / d f \times C A S A / R k) \times D F / B-d f / d f$, we confirmed the assignment of $d f$ to mouse chromosome 11 and demonstrated recombination between $d f$ and the growth hormone gene. This backeross is an invaluable resource for screening candidate genes for the $d f$ mutation. The $d f$ locus maps to less than $1 \mathrm{cM}$ distal to $P a d-1(0.85 \pm 0.85 \mathrm{cM})$. Two new genes localized on mouse chromosome 11, Rpo2-1, and Edp-1, map to a region of conserved synteny with human chromosome 17. The localization of the $\alpha_{1}$ adrenergic receptor, Adra-1, extends a known region of synteny conservation between mouse chromosome 11 and human chromosome 5 , and suggests that a human counterpart to $d f$ would map to human chromosome 5. 1981 Academic Press, Inc.
\end{abstract}

\section{INTRODUCTION}

The recessive allele, $d f$, results in severe proportional dwarfism in the Ames dwarf mouse (Fig. 1). Although $d f$ homozygotes are indistinguishable from normal mice at birth, the growth insufficiency, characteristic face, and small pinnae are evident by 3 weeks of age. The phenotypic characteristics of this hypopituitary mutant, including dwarfism, hypothyroidism, and infertility, can be attributed to lack of growth hormone, prolactin, and thyroid-stimulating hormone (Cheng et al., 1983; Bartke, 1965b). Various studies suggest that the mutation results in a failure to initiate synthesis of pituitary hormones during development (Slabaugh et al., 1982; Lieberman et al., 1983). Adult $d f / d f$ mice are approximately half the weight of their wild-type littermates, yet their pituitary glands are disproportionately smaller due to the

\footnotetext{
${ }^{1}$ To whom correspondence should be addressed.
}

hypocellularity of the anterior lobe (Camper and Lloyd, unpublished observations; Cheng et al., 1983). Growth hormone, prolactin, and thyroid stimulating hormone are normally produced in specialized cells known as somatotrophs, lactotrophs, and thyrotrophs, respectively. Each of these cell types is distinguished by cell morphology and by the characteristics of the secretory granules. Ultrastructural studies show no evidence of these cell types in the pituitaries of $d f / d f$ mice, but do reveal the presence of an unusual, nongranular, cell type unique to dwarf pituitaries (Cheng et al., 1983). This unusual cell type may represent a developmental precursor to the cell types which are missing in $d f / d f$ mice. By this model, the $d f$ mutation may result in a block in the differentiation of this nongranular cell type into the somatotroph, lactotroph, and thyrotroph cells.

Snell dwarf mice $(d w / d w)$ have a phenotype nearly identical with that of the $d f / d f$ mice, but $d w$ and $d f$ are not allelic (O'Hara et al., 1988; Bartke, 1965a). Occasional $d f / d f$ males are fertile (Bartke, 1965b), while $d w / d w$ mice are uniformly sterile. This difference may be related to the fact that exhaustive searching reveals extremely rare clusters of somatotrophs and occasional thyrotrophs and lactotrophs in $d f / d f$ but not $d w / d w$ pituitaries (Camper and Lloyd, unpublished observations; Roux et al., 1982). These and other subtle differences in the phenotypes of $d f / d f$ and $d w / d w$ mice (reviewed in Bartke, 1979) could result from either the nature of the lesions or the different genetic backgrounds which carry the mutations. The basic similarity of the phenotypes, however, suggests that both $d f$ and $d w$ gene products have important roles in the differentiation of somatotrophs, lactotrophs, and thyrotrophs from a common precursor.

The $d w$ mutation has recently been identified as a lesion in the Pit-1 gene (Camper et al., 1990; Li et al., 1990). Pit-1, a homeobox-containing gene, is expressed specifically in the anterior pituitary gland and is important for transcription of the prolactin and growth hormone genes (Bodner et al., 1988; In- 


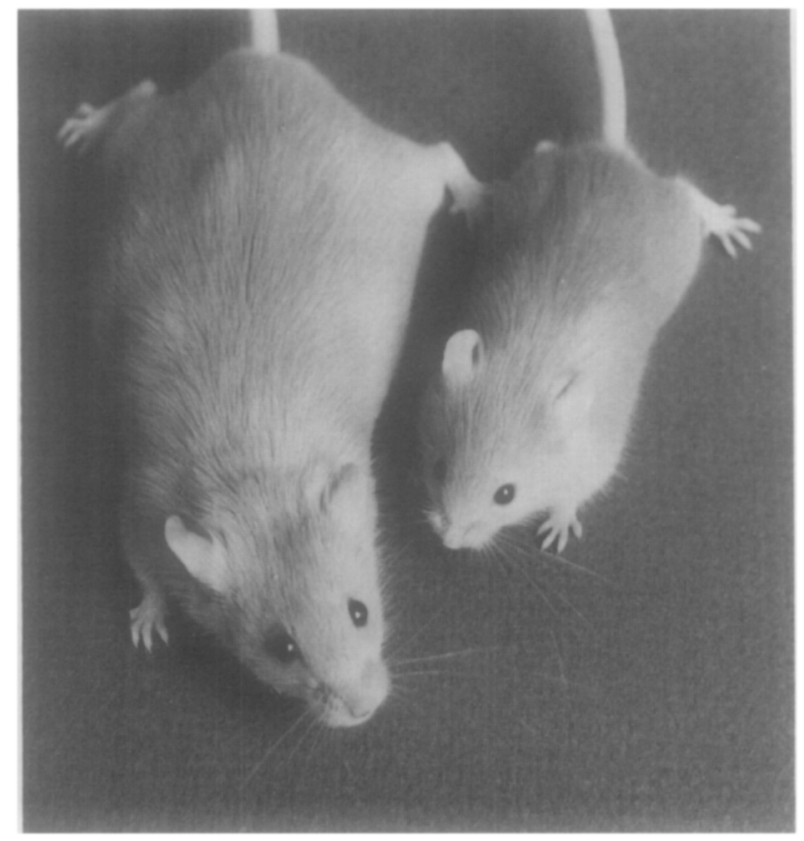

FIG. 1. Severe proportionate dwarf phenotype of $d f / d f$ mice. The 3-month-old female $d f / d f$ mouse (right) weighs $11 \mathrm{~g}$, and the age-matched female $d f /+$ mouse (left) weighs $37 \mathrm{~g}$. Note the characteristic face shape of the dwarf.

graham et al., 1988; Mangalam et al., 1989; Simmons et al., 1990). The lack of Pit-1 in $d w / d w$ mice results in the deficiency of multiple pituitary cell types, demonstrating that Pit-1 is required for pituitary differentiation. Pituitaries of $d f / d f$ mice contain only trace levels of Pit-1 mRNA and little or no PIT-1 protein (Camper et al., 1990; Li et al., 1990). Thus, the products of at least two genes, $d f$ and Pit-1, are required to complete the cell specialization process and the $d f$ gene product may be required for Pit-1 expression. These two mouse mutations provide a unique opportunity to study pituitary cell differentiation. The cloning of the $d f$ gene will be an important step in the understanding of this developmental pathway.

The $d f$ mutation was identified in the descendants of an X-irradiation experiment (Schaible and Gowen, 1961). Data have been presented that suggest linkage of $d f$ to the phenotypic marker rex $(R e)$, on Chr 11 (Bartke, 1965a). To confirm the assignment of $d f$ to $\mathrm{Chr} 11$ and to localize $d f$, we have constructed an intersubspecific backcross between the line which carries the $d f$ gene (DF/B- $d f / d f)$ and Mus musculus castaneus, a distantly related subspecies (Bonhomme $e t$ $a l ., 1984)$. The evolutionary distance between the DF/ $\mathrm{B}$ and $M$. castaneus subspecies results in DNA sequence diversity which can be exploited to facilitate the identification of restriction length polymorphisms (RFLPs). While it is possible that the distance between these two subspecies could produce re- combinational hot-spots or zones of suppression due to an accumulation of rearrangements and deletions, most interspecific and intersubspecific backcrosses have generated data consistent with linkage information obtained by other means (Avner et al., 1988). Using RFLPs, we can distinguish $d f / d f$ from $M$. castaneus DNA at each locus and determine recombinational distances. We used five loci previously mapped in a $M$. spretus and C57BL/6J interspecies backcross (Buchberg et al., 1989) as markers in our backcross. These anchor loci, Erbb, Pad-1, Csfgm, Myhs, and $E r b a$, span $46 \mathrm{cM}$ in our backcross.

We have established an intersubspecific backcross map of the segment of Chr 11 near $d f$ for use in screening candidate genes and positional cloning. Thus far, we have identified molecular markers 0.85 $\mathrm{cM}$ proximal and $2.6 \mathrm{cM}$ distal to $d f$. We also report the localization of three genes not previously mapped. One of these suggests an extension of the known region of homology conservation between mouse Chr 11 and human Chr 5.

\section{MATERIALS AND METHODS}

\section{Mice}

Mice carrying the Ames dwarf mutation (referred to herein as DF/B) were generously provided by Dr. A. Bartke, Southern Illinois University (Carbondale, IL). DF/B is not well defined genetically and has not been systematically inbred. The current line is probably fairly homogeneous, however, because it was derived from a limited number of mating pairs (Bartke, personal communication).

To correct infertility, homozygous dwarf males were injected with thyroid hormone (T4, Sigma T-0397) and ovine growth hormone (National Hormone Pituitary Program) three to five times weekly (O'Hara et al., 1988). Homozygous females were treated with thyroid hormone to induce some growth, then pituitary tissue from normal female sibs was grafted under the kidney capsule (Soares et al., 1984). Such grafts produced sufficient prolactin to maintain pregnancy and lactation. Grafted females produced multiple litters (up to 6) with an average of four pups per litter. After establishing fertility, dwarf mice can be maintained on AIN-76A, a diet containing $25 \mathrm{mg}$ thyroid powder $/ \mathrm{kg}$ (US Biochemicals) (Eicher and Beamer, 1980).

Inbred $M$. musculus castaneus mice (F40) were purchased from The Jackson Laboratory (Bar Harbor, $\mathrm{ME})$. The (DF/B-df/df $\times C A S A / R k) \times \mathrm{DF} / \mathrm{B}-d f / d f$ backcross (Camper et al., 1990) was performed at The University of Michigan (Ann Arbor, MI). Progeny of the backcross were killed at 4-6 weeks of age. Of the 492 progeny collected, 221 were typed as $d f / d f$ and 271 
as $d f /+$, based on their phenotype. Animals which could not be typed unambiguously at the $d f$ locus (less than $1 \%$ ) were excluded from analysis. These experiments were approved by the University of Michigan Committee on Use and Care of Animals and all animals were housed and cared for according to NIH guidelines.

\section{DNA Isolation and Southern Hybridization.}

Liver, kidney, lung, and spleen from 492 backcross animals were snap frozen in liquid nitrogen and stored at $-70^{\circ} \mathrm{C}$. High molecular weight genomic DNA was made from tissues of 132 of these animals by proteinase $\mathrm{K}$ and RNAase treatment followed by phenol/chloroform extraction and ethanol precipitation. Restriction digests were performed on 8-12 $\mu \mathrm{g}$ of genomic DNA and the fragments were separated by electrophoresis on $0.8 \%$ agarose gels. Southern blots were performed as described previously (Sambrook $e t$ al., 1989). All gels were transferred to Zeta-Probe nylon membranes (Bio-Rad).

\section{Probes}

All probes were labeled using the hexanucleotide technique (Feinberg and Vogelstein, 1982) with $[\alpha-$ $\left.{ }^{32} \mathrm{P}\right] \mathrm{dCTP}(10 \mathrm{mCi} / \mathrm{ml})$ from Amersham (Arlington Heights, IL). The avian erythroblastosis virus oncogene B, Erbb (or epidermal growth factor receptor) was mapped with a 1.84-kb EcoRI fragment of the chicken Erbb cDNA (ATCC). The Adra-1 probe, approximately $2 \mathrm{~kb}$ of hamster cDNA cloned into the $E c o$ RI site of SP65, was purchased from Dr. R. J. Lefkowitz at Duke University Medical Center. Pad-1, a 1.7-kb EcoRI-PstI fragment of unique mouse genomic DNA sequences adjacent to a mouse mammary tumor virus insertion site and cloned into pUC19, was a gift of Dr. A. Sonnenberg, Central Laboratory of the Netherlands Red Cross Blood Transfusion Service. The Sparc probe (pC33) was a 1.1-kb fragment of mouse osteonectin genomic DNA cloned into the BamHI site of pGEM-1, courtesy of Dr. M. Young, National Institute of Dental Research. We used mouse cDNA probes provided by Dr. W. Paul, National Institute of Health, to map Csfgm (a 780-bp BamHI-EcoRI fragment) and $I l-3$ (a 600-bp PstI fragment). Myhs was mapped with the Myh-1 probe which contains $1252 \mathrm{bp}$ of mouse $\mathrm{cDNA}$ sequence and was provided by Dr. N. Copeland, National Cancer Institute. Rpo2-1 was mapped with pBE2.9, a 2.9-kb BamHI-EcoRI fragment of mouse large subunit of RNA polymerase II, from Dr. M. Bartolomei, Princeton University. The Asgr-1 locus was mapped with a 1.4-kb EcoRI fragment of mouse cDNA homologous to rat hepatic lectin $2 / 3$, received from Dr. J. Sanford, Roswell Park Cancer Institute. Edp-1, an endothelial cell protein, was mapped with a probe obtained from Dr. V. Dixit, University of Michigan. Erba was mapped with a $1.3-\mathrm{kb}$ SalI-XhoI fragment of rat cDNA obtained from Dr. R. Koenig, University of Michigan. Gh was typed with a 1.3-kb EcoRI fragment of the bovine gene from Dr. F. Rottman, Case Western Reserve University (Woychik et al., 1982), and with a murine cDNA generated by reverse transcription of mouse pituitary RNA followed by a polymerase chain reaction (PCR) with synthetic oligonucleotides (Krug and Berger, 1987; Saiki et al., 1988) designed from the published mRNA sequence (Linzer and Talamantes, 1985). The sequences of the oligonucleotide primers were 5 -GG GGA TCC GAG TCC TGT GGA GAG ATC ACT GCT TGG-3' and 5'-GG AAG CTT ACA GGA GAG TGC AGC AGA GAC ACT GG-3', corresponding to nucleotides 33 to 59 and 720 to 743 , respectively.

\section{Statistical Analysis}

Genetic distances are given in centimorgans (cM) with the estimated standard deviation. The estimated standard deviation is calculated as the square root of the variance. The variance is equal to $p(1-p) / n$, where $p$ is the recombinant fraction and $n$ is the number of individuals. Where a $95 \%$ confidence interval is used (1.96 $\times$ standard deviation), it is expressly stated.

Lod scores were calculated as $\log _{10}\left[r^{x}(1-r)^{y}\right.$ $\left.\div(0.5)^{(x+y)}\right]$, where $r$ is the recombinant fraction, $x$ is the number of recombinants, and $y$ is the number of nonrecombinants.

\section{RESULTS}

\section{Confirmation of the Location of df on Chr 11 by Linkage to Myhs}

To confirm the assignment of $d f$ to $\mathrm{Chr} 11$, individual progeny of the backcross (DF/B-df/df $\times C A S A /$ $R k) \times \mathrm{DF} / \mathrm{B}-d f / d f$ were scored by phenotype as either $d f / d f$ or $d f /+$ and typed at the Myhs locus by Southern blotting. Genomic DNA samples obtained from DF/ B-df/df and $M$. castaneus stocks, and the heterozygous (DF/B- $d f / d f \times C A S A / R k) \quad \mathrm{F}_{1}$ progeny were digested with various restriction endonucleases and the fragments were blotted into filters. A RFLP unique to the $M$. castaneus allele of $M y h s$ was detected with HincII (Fig. 2; Table 1). Only six of 132 backcross progeny examined exhibited recombination between $d f$ and $M y h s$, demonstrating linkage of $d f$ to a gene on Chr 11. The genetic distance between $d f$ and $M y h s$ is $4.5 \pm 1.8 \mathrm{cM}$.

\section{Segregation Analysis of the Anchor loci Erbb, Pad-1,} Csfgm/Il-3, Myhs, and Erba

Having confirmed the location of $d f$ on Chr 11 by demonstrating linkage of $d f$ to $M y h s$, we extended our analysis to include several additional loci on Chr 11 . 

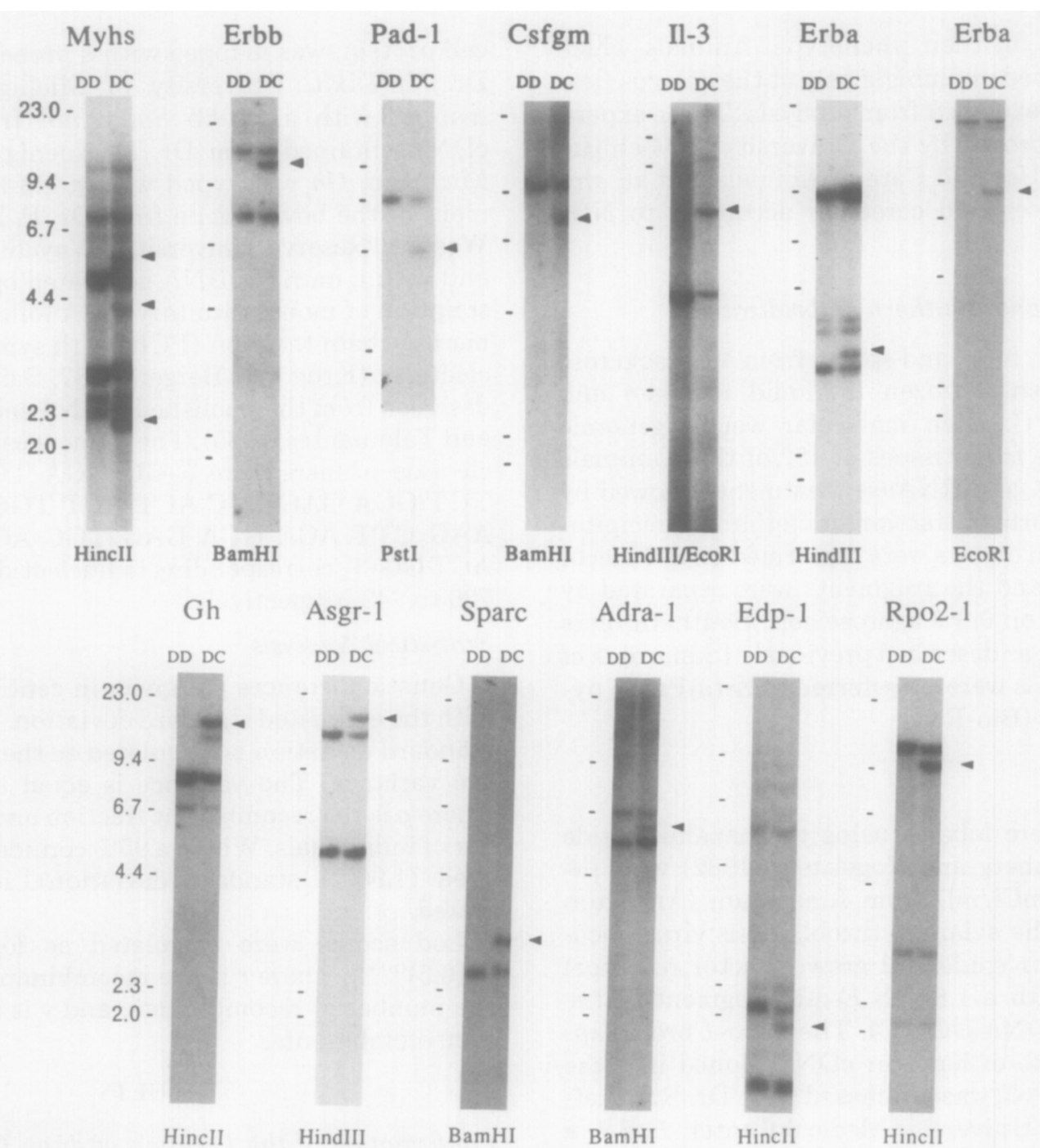

FIG. 2. Southern blot identification of unique $M$. castancus RFLPs in 12 genes. Arrowheads signify bands present in DNA from (DF/B-df/df $\times M$. castaneus) F1 mice (DC) but absent in homozygous DF/B-df/df (DD) mice. The restriction enzymes used to produce the informative bands are indicated below each panel. The molecular weight standards are indicated at the left in kb. Some individuals were typed at $E r b b$ with TaqI instead of BamHI and at Asgr-I with BamHI instead of HindIII.

One hundred seventeen backcross progeny were typed for the anchor loci Erbb, Pad-1, Csfgm/Il-3, and Erba. These loci were previously typed with an interspecific backcross $[(\mathrm{C} 57 \mathrm{BL} / 6 \mathrm{~J} \times M$. spretus $)$ $\times$ C57BL/6J], and found to span $48 \mathrm{cM}$ (Buchberg $e t$ al., 1989). Csfgm and $I l-3$ are considered identical at the level of detail of this map because they are only 9 $\mathrm{kb}$ apart (Yang et al., 1988) and they cosegregate in our backcross (data not shown).

Genomic DNA from progeny of the backcross (DF/ B- $d f / d f \times C A S A / R k) \times \mathrm{DF} / \mathrm{B}-d f / d f$, was digested with restriction endonucleases which allowed the $M$. castaneus allele of each gene to be distinguished from the DF/B allele (Fig. 2; Table 1). At each locus, progeny displayed either the homozygous DF/B-df/df pattern (DD) or the heterozygous (DF/B-df/df $\times C A S A$ / $R k) F_{1}$ pattern (DC). One individual displayed a rare polymorphism at the Pad-1 locus which was not evident in any of the 15 other backcross progeny from the same mating pair. Minimization of crossover frequency between these anchor loci (Fig. 3) gave the following gene order and distance estimates ( \pm standard deviation): (centromere)-Erbb-17.0 $\pm 3.5 \mathrm{cM}$ Pad 1-0.85 $\pm .85 \mathrm{cM}-d f-2.6 \pm 1.5 \mathrm{cM}-$ Csfgm $/ I l-3-1.9$ $\pm 1.8 \mathrm{cM}-M y h s-23.7 \pm 4.1 \mathrm{cM}-E r b a$. Assuming this gene order, there were 52 recombination events over a total distance of $46.1 \pm 4.6 \mathrm{cM}$, including two double crossovers, in the 117 animals. All alternative orders result in multiple double or greater crossover events within a short genetic distance. The data demonstrates that $d f$ is located on Chr 11 in the interval between Csfgm/Il-3 and Pad-1.

Thyroid hormone receptors constitute a family of proteins which are separated according to amino acid 
TABLE 1

RFLPs Used for df Linkage Analysis

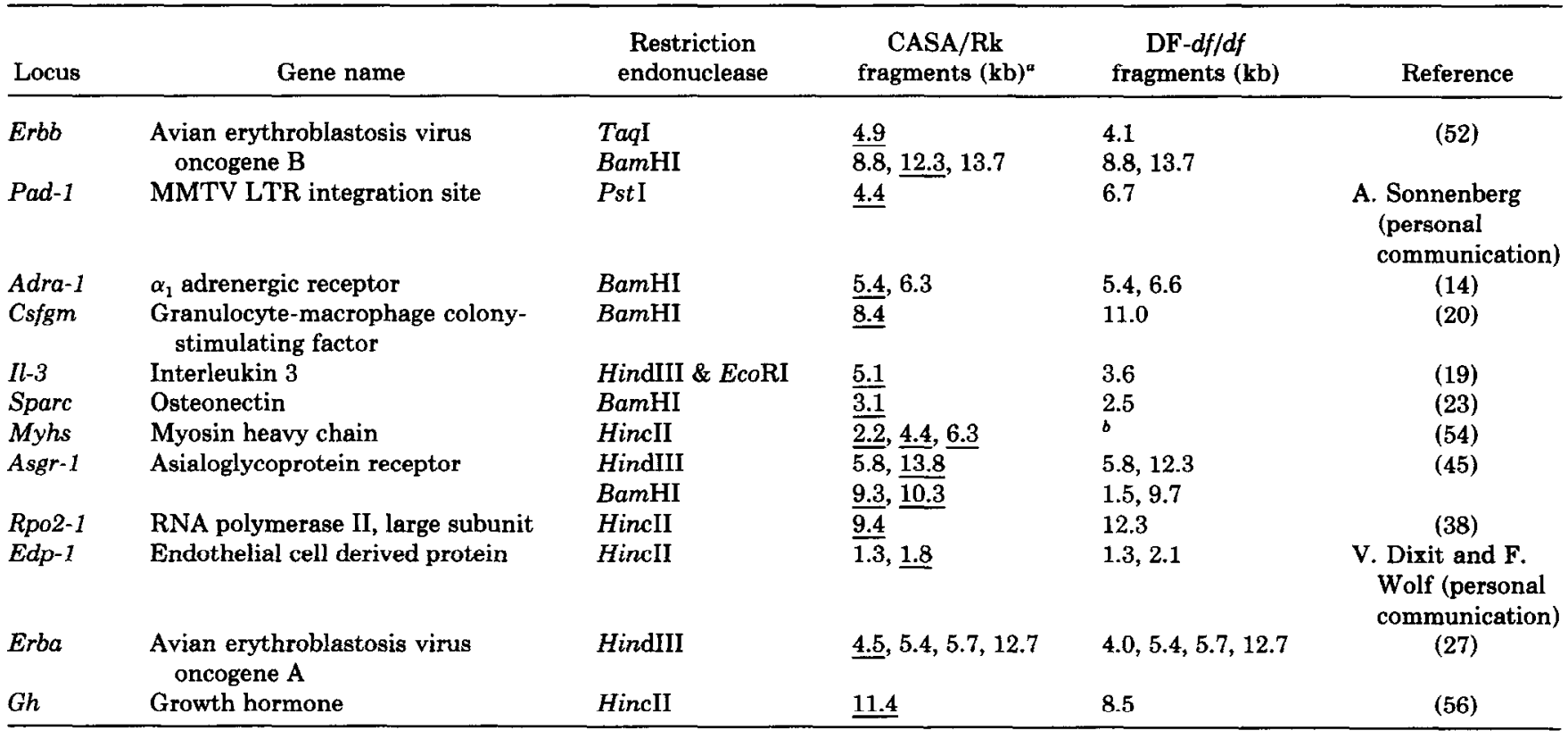

${ }^{a}$ Underlined restriction fragment sizes indicate the restriction fragments used for typing the intersubspecific backcross progeny. Molecular weights were determined by comparison to molecular weight standards and are reported in kilobases (kb).

b Myhs appears as a complex pattern of greater than 10 bands on Southern blots of $M$. castaneus (CASA/Rk) and DF/B-df/df genomic DNA. Only the bands specific to the $M$. castaneus allele of $M y h s$ are tabulated.

sequence homology into two major subtypes, $\alpha$ and $\beta$. There are several $\alpha$ forms in rats, $\alpha-1, \alpha-2$, and $\alpha-3$, which are alternate splice products of the same gene. There are also at least two $\beta$ receptor proteins, $\beta-1$ and $\beta-2$, which are approximately $80 \%$ homologous to the $\alpha$ protein (Hodin et al., 1989). We used the rat $\alpha-2$ cDNA to probe for the thyroid hormone receptor in the mouse. Both HindIII and EcoRI polymorphisms (Erba, Fig. 2) were used to map the $\alpha$ thyroid hormone receptor on mouse $\mathrm{Chr} 11$. A $\beta$-specific probe was used to verify that the $\beta$ thyroid hormone receptor maps elsewhere in mice (data not shown).

\section{Recombination between $d f$ and $G h$}

The growth hormone gene $(G h)$ has been considered as a candidate gene for the $d f$ mutation, although it is not obviously rearranged in $d f$ mice (Phillips et al., 1982; Slabaugh et al., 1982). Because $G h$ has been assigned to mouse Chr 11 (Jackson-Grusby et al., 1988), the backcross progeny were tested for recombination between the two genes. Using a bovine growth hormone probe, we detected a polymorphism with HincII and typed 40 backcross progeny. To obtain a stronger signal, we developed a mouse growth hor-

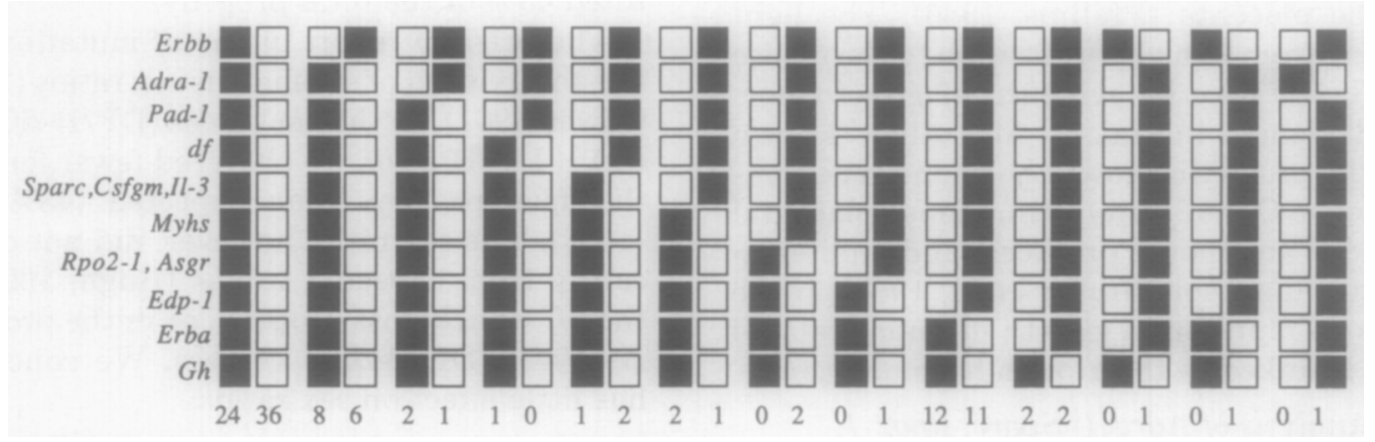

FIG. 3. Analyses of intersubspecific backcross haplotypes. Each column represents a chromosomal haplotype identified in the backcross progeny that was inherited from the (DF/B-df/df $\times M$. castaneus) $\mathrm{F}_{1}$ parent. The number of backcross progeny with each observed haplotype is indicated at the bottom of each column. Open boxes represent the DF alleles and closed boxes represent the $M$. castaneus alleles as determined by Southern blotting with probes for the loci indicated at the left. Adra-1 and Edp-1 were typed in 98 and 107 animals, respectively. All other loci were typed in 117 backcross progeny. 


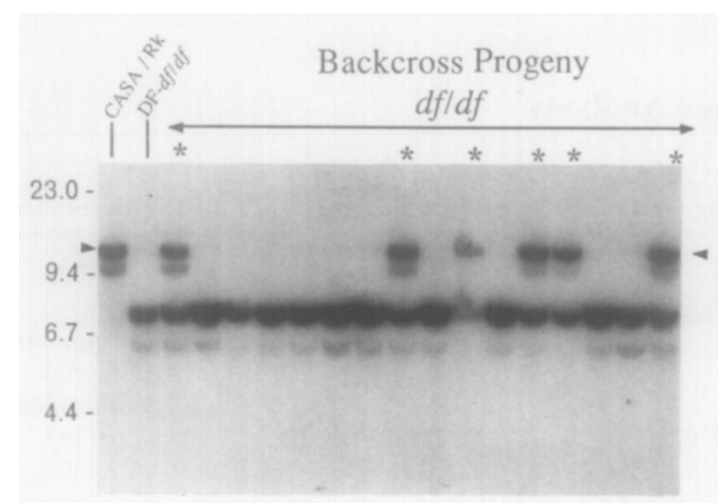

FIG. 4. Recombination between the loci for $d f$ and growth hormone. Genomic DNA samples from the inbred stocks $M$. castaneus (CASA/Rk) and DF/B-df/df and $d f / d f$ progeny of the backcross [(DF/B-df/df $\times M$. castaneus $) \times \mathrm{DF} / \mathrm{B}-d f / d f]$ were digested with the restriction enzyme IIincII, separated by electrophoresis on an agarose gel, transferred to a nylon membrane and hybridized with the mouse $G h$ cDNA probe. Filters were washed under mild stringency conditions ( $0.5 \times \mathrm{SSC}$ and $0.1 \% \mathrm{SDS}$ at $\left.57^{\circ} \mathrm{C}\right)$ and exposed to X-ray film. The RFLP characteristic of the $M$. castaneus allele of the $G h$ gene is indicated by the arrowheads. Molecular weight markers are indicated at the left in $\mathbf{k b}$. The six backcross progeny homozygous at the $d f$ locus but heterozygous at the $G h$ locus are denoted with an asterisk.

mone cDNA probe by reverse transcription of mouse pituitary mRNA followed by PCR with oligonucleotide primers designed from the published sequence of the mouse growth hormone mRNA (Linzer and Talamantes, 1985). Using this probe, we confirmed the results obtained with the bovine probe and tested the remaining backcross progeny. A total of 38 crossovers between $G h$ and $d f$ were observed in 117 individuals examined (Fig. 3). The data indicate that $G h$ is 32.5 $\pm 4.3 \mathrm{cM}$ distal to the $d f$ gene. Six $d f / d f$ backcross progeny carrying the $M$. castaneus allele of the growth hormone gene are illustrated in Fig. 4.

The human growth hormone gene cluster contains five genes, including an expressed and a silent form of the growth hormone gene and several forms of the evolutionarily related chorionic somatomammotropin gene (placental lactogen), two of which are expressed in the placenta (Phillips, 1985). The light bands resulting from weak hybridization to the mouse Gh probe (Fig. 4) may be evidence of growth hormone-related genes in mice. All other known members of the prolactin-growth hormone gene family map to mouse $\mathrm{Chr} 13$ (prolactin, mouse placental lactogen I and II and mouse proliferin and proliferinrelated protein) (Jackson-Grusby et al., 1988). If the lighter bands do represent a growth hormone related gene, then it is linked to the growth hormone gene.

Segregation Analysis of Adra-1, Sparc, Rpo2-1, Asgr-1, and Edp-1

Having validated our backcross with $E r b b, P a d-1$, $C s f g m / I l-3$, and $E r b a$, we used it to localize several additional genes. The segregation pattern of the Adra-1, Sparc, Rpo2-1, Asgr-1, and Edp-1 alleles in the intersubspecific backcross progeny indicated that all of these genes are located on Chr 11 (Table 1; Fig. 3). All loci were typed in 117 animals except Adra-1, and $E d p-1$. The $\alpha_{1}$ adrenergic receptor, Adra-1, was mapped between Pad-1 and Erbb to a position 5.1 $\pm 2.2 \mathrm{cM}$ proximal to $d f$ ( 5 recombinants in 98 animals tested). Asgr-1, the asialoglycoprotein receptor, was mapped $6.7 \pm 2.3 \mathrm{cM}$ distal to $d f$ (8 recombinants). The large subunit of RNA polymerase II, $R p o 2-1$, was mapped to be $6.8 \pm 2.3 \mathrm{cM}$ distal to $d f(8$ recombinants). No gene order could be determined between Rpo2-1 and Asgr-1 because no crossovers were found between these loci. Sparc (osteonectin) was placed $2.6 \pm 1.5 \mathrm{cM}$ distal to $d f$ (3 recombinants). No gene order could be determined between Sparc, Csfgm, and Il-3. Edp-1 was mapp̀ed between Myhs and Erba at a position $7.5 \pm 2.5 \mathrm{cM}$ distal to $d f(8$ recombinants in 107 animals tested).

\section{DISCUSSION}

\section{Validation of the DF Backcross}

The $d f$ mutation was discovered in breeding a line of extreme nonagouti $\left(a^{e} a^{e}\right)$ mice which were derived from a cross between Goodale's "large" mice and a stock descended from an X-irradiation experiment (Schaible and Gowen, 1961). Genetic background can have tremendous impact on the phenotype of a mutation. For example, the Snell dwarf mutation $(d w)$ has a more severe phenotype and results in lower viability on the C57BL6/J background (Beamer, personal communication). $M$. castaneus mice are approximately 15 to $20 \mathrm{~g}$, much smaller than the wild type mice from the stock which carries the $d f$ mutation. The phenotype of $d f / d f$ mice was evident, however, among the backcross progeny. The hybrid vigor of the $d f /+$ progeny may have emphasized the difference between the $d f /+$ and $d f / d f$ progeny. Mice typed as $d f / d f$ were approximately half the weight of the $d f /+$ progeny and they constituted $45 \%$ of the total progeny.

The original report of the $d f$ mutation mentioned the observation of anomalous sex ratios (Schaible and Gowen 1961). In the backcross (DF/B- $d f / d f \times C A S A /$ $R k) \times \mathrm{DF} / \mathrm{B}-d f / d f$, we observed fewer females among the $d f / d f$ progeny than expected $(43 \%$ females, $P$ $<3 \%$ ). The sex ratio, however, did not differ significantly from expected values (Rugh, 1990) in either the $d f /+$ backcross progeny, or in the progeny of DF/ $\mathrm{B}-d f / d f \times \mathrm{DF} / \mathrm{B}-d f /+$ crosses. We conclude that $d f$ has little effect on sex ratios.

\section{The df Gene is Located on Chr 11}

The original description of the $d f$ mutation suggested linkage of $d f$ to $R e$ and $w a-2$, but no data were 
presented describing the crosses or progeny (Schaible and Gowen, 1961). Subsequently, the linkage of $d f$ to $R e$ was reported from two crosses (Bartke, 1965a). With $d f$ and $R e$ in coupling ( $d f \mathrm{Re} /++$ ), 40 recombinants in 219 animals were observed, yielding an estimated distance of $18.3 \pm 2.6 \mathrm{cM}$. With $d f$ and $R e$ in repulsion $(d f+/+R e), 41$ recombinants were observed in 119 animals, yielding the larger distance estimate of $34.5 \pm 4.4 \mathrm{cM}$. The lod scores for linkage are 20.7 and 2.54 if the data from the crosses are analyzed individually and 21.1 if the data are combined. In spite of the lack of obvious explanation for the different genetic distance estimates, this data is highly suggestive of linkage of $d f$ and Re on Chr 11. To confirm the assignment of $d f$ to $\mathrm{Chr} 11$, we typed progeny of the backcross $(C A S A / R k \times \mathrm{DF} / \mathrm{B}-d f / d f) \times \mathrm{DF} / \mathrm{B}-d f / d f$ at the $M y h s$ locus using an RFLP. Myhs has been localized on $\mathrm{Chr} 11$ by independent interspecific backcross analyses (Buchberg et al., 1989; Weydert et al., 1985; Robert et al., 1985). Analysis of 132 backcross progeny demonstrated that $M y h s$ and $d f$ are closely linked $(4.5 \pm 1.8 \mathrm{cM})$ and ruled out the possibility that the $d f$ gene was on a mouse Chr other than 11 .

Segregation Analysis of the Anchor Loci Erbb, Pad-1, Csfgm/Il-3, Myhs, and Erba

We have confirmed the gene order previously published for Erbb, Pad-1, Csfgm, Myhs, and Erba, as determined with a (C57BL/6J $\times M$. spretus $) \times \mathrm{C} 57 \mathrm{BL} /$ $6 \mathrm{~J}$ backcross (Buchberg et al., 1989). The $d f$ locus is between Pad-1 and Csfgm/Il-3. By comparison of our linkage map with the map compiled by The Jackson Laboratory (Fig. 5), we estimate $d f$ to be $26 \mathrm{cM}$ distal to $R e$. This location corresponds very well with that predicted by classical genetic mapping of $d f$ (Bartke, 1965a).

Distinguishing DF/B alleles from $M$. castaneus alleles was not difficult for any of the 12 loci reported here. Genetic heterogeneity of the DF/B stock was not evident. With only one exception, all animals tested at all 12 loci displayed the pattern expected from a $d f / d f$ or a $(\mathrm{DF} / \mathrm{B}-d f / d f \times C A S A / R k) \mathrm{F}_{1}$ genotype. For future studies, we have begun to transfer the df gene onto a $\mathrm{C} 3 \mathrm{HeB} / \mathrm{FeJ}$ background $(N=4$; Scarlett and Camper, unpublished). The phenotype of C3H.DF/Umi-df/df mice is similar to that of DF/B$d f / d f$ mice.

The genetic distances between the five anchor loci observed in our backcross [(DF/B-df/df $\times C A S A / R k)$ $\times \mathrm{DF} / \mathrm{B}-d f / d f]$ span a large portion $(46.2 \pm 4.6 \mathrm{cM})$ of Chr 11. Overall, the distances reported here do not differ significantly from previously published values, suggesting that a gross rearrangement of $\mathrm{Chr} 11$ in $d f$ mice is unlikely (Fig. 5). Although the distance from Pad-1 to Myhs appears to be compressed in the back- cross segregating $d f$, the difference is not statistically significant because the $95 \%$ confidence limits of the two sets of data overlap $(6.0 \pm 4.3 \mathrm{cM}$ vs $12.5 \pm 5.4$ $\mathrm{cM}$ ). Moreover, a smaller interval containing $d f(\mathrm{Pad}$ 1 to $I l-3)$ compares well with published values. The possibility of a small deletion or insertion in the immediate region around $d f$ will be addressed with pulse field gel electrophoresis using probes for closely linked molecular markers.

\section{Localization of df on Chr 11 Eliminates Several Candidate Genes for the df Mutation}

With this study, the structural genes for the hormones whose expression is deficient in $d f / d f$ mice can be eliminated as candidate genes for the $d f$ mutation based on their chromosomal locations. Thyroid stimulating hormone is a dimeric glycoprotein composed of $\alpha$ and $\beta$ subunits. The genes for these subunits are located on mouse Chr 4 and 3, respectively (Naylor et $a l$. , 1983). The prolactin gene has been mapped to mouse Chr 13 by analysis of somatic cell hybrids (Jackson-Grusby et al., 1988). Thus, demonstrating linkage of $d f$ to molecular markers on Chr 11 eliminated both the thyroid stimulating hormone genes and prolactin gene from consideration.

The growth hormone gene was assigned to mouse Chr 11 by analysis of somatic cell hybrids (JacksonGrusby et al., 1988). Mutations in Gh might be expected to lead to isolated growth hormone deficiency, as is the case in humans and rats (Phillips, 1985; Charlton et al., 1988; Takeuchi et al., 1990). Nevertheless, to conclusively eliminate $G h$ as a candidate for $d f$, we mapped $G h$ in the backcross segregating $d f$, and determined that $G h$ is $32.5 \pm 4.3 \mathrm{cM}$ distal to the $d f$ gene. Our localization of the mouse growth hormone gene is consistent with the location expected from mapping the human gene to HSA 17q22-q24 (Solomon and Barker, 1989) and the synteny conservation between human Chr 17 and mouse Chr 11 (Buchberg et al., 1989). Recent reports which mapped the mouse Gh gene with recombinant inbred (RI) lines and interspecific backcrosses also place the gene on the distal portion of Chr 11, consistent with our data (Eicher and Lee, 1990; Elliott et al., 1990).

A locus (or set of loci) which effects fetal growth has been reported on mouse Chr 11 (Cattanach and Kirk, 1985). Mice disomic for $\mathrm{Chr} 11$, produced by intercrossing heterozygotes for the translocation $\mathrm{Rb}(11.13) 4 \mathrm{Bnr}$, differ by one-third in size from their littermates at birth, and the nature of the size difference is apparently influenced by imprinting. This locus and $d f$ are located within the proximal portion of Chr 11; however, $d f$ does not have an effect on fetal 


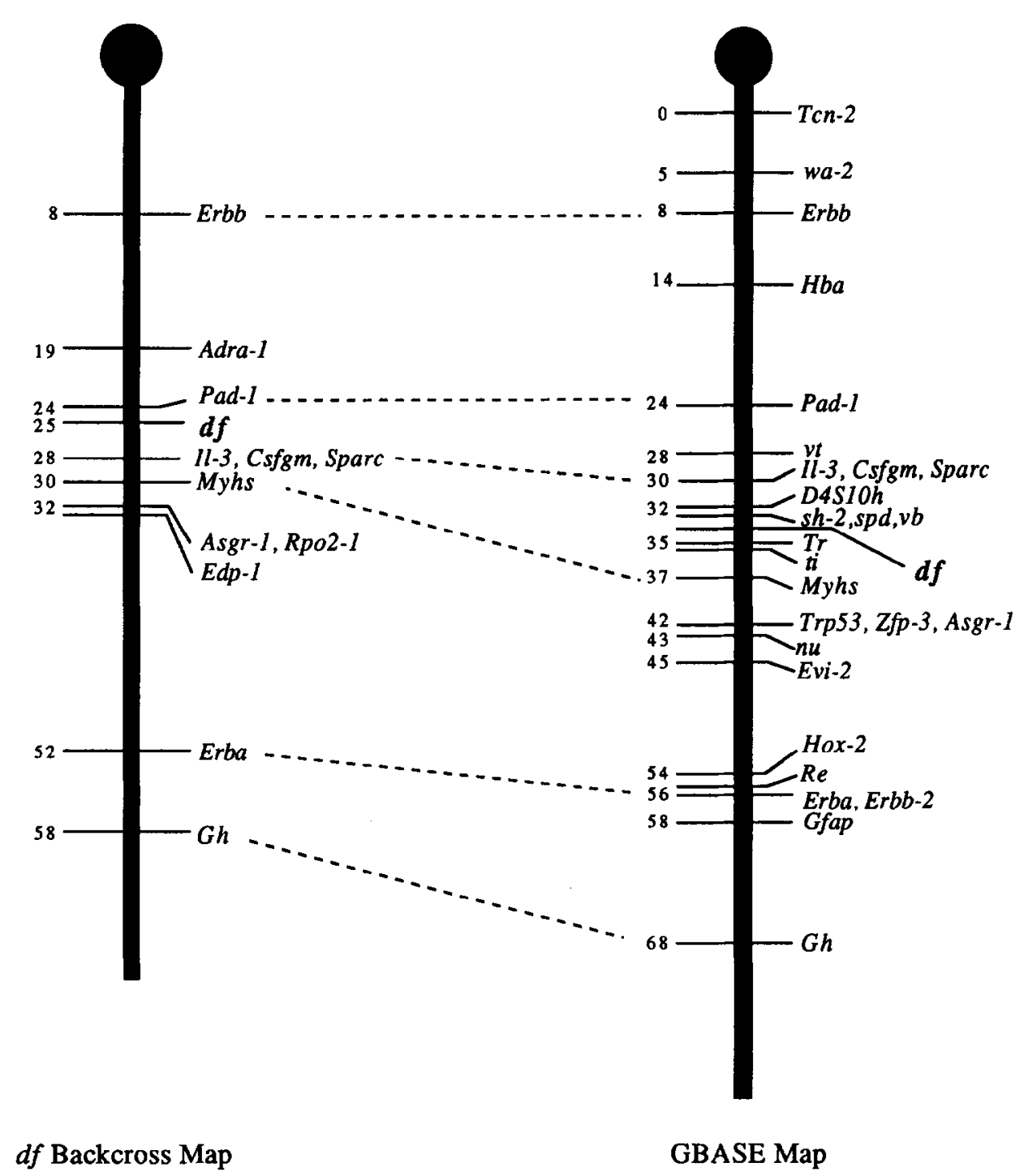

FIG. 5. Linkage map of mouse Chr 11. The chromosome on the right is the linkage map of mouse Chr 11 taken from the Jackson Laboratory GBASE mouse map which combines data generated by a variety of methods. The chromosome on the left presents the data generated by our intersubspecific backcross analysis, assuming that the distance from Erbb to the centromere is identical to Jackson Laboratory values. The individual loci are labelled on the right of the chromosome and their distances in cM from the centromere is on the left.

growth. ${ }^{2}$ The primary effect of $d f$ is on pituitary cytodifferentiation, and pituitary hormones are not required for fetal growth (Rimoin and Schimke, 1971). Thus $d f$ is likely to be distinct from the locus described in mice disomic for $\mathrm{Chr} 11$. Further studies are required to confirm this.

The precise mapping of the $d f$ gene has permitted the elimination of a number of growth factors and growth factor receptors as candidate genes. These in-

\footnotetext{
${ }^{2} d f / d f$ Day 1 newborns do not differ in size from their wild-type littermates $(1.50 \pm 0.27 \mathrm{~g}, n=68$ ) (Scarlett and Camper, unpublished observations).
}

clude the receptors for epidermal growth factor $(E r b b)$, and thyroid hormone (Erba), two agents which influence the transcription of pituitary hormone genes and could have an impact on pituitary differentiation. The hypocellularity of the $d f / d f$ pituitary gland suggests that the primary site of $d f$ action is in the pituitary, although $d f$ may he expressed in the hypothalamus or other tissues. Certain hypothalamic releasing factors, their receptors, and other genes that might be expected to affect growth if they were mutated (McKusick, 1989) have not yet been mapped in the mouse. As these factors and receptors are cloned they will be tested for linkage to $d f$ using this backcross. 
TABLE 2

Comparative Mapping of Selected Loci

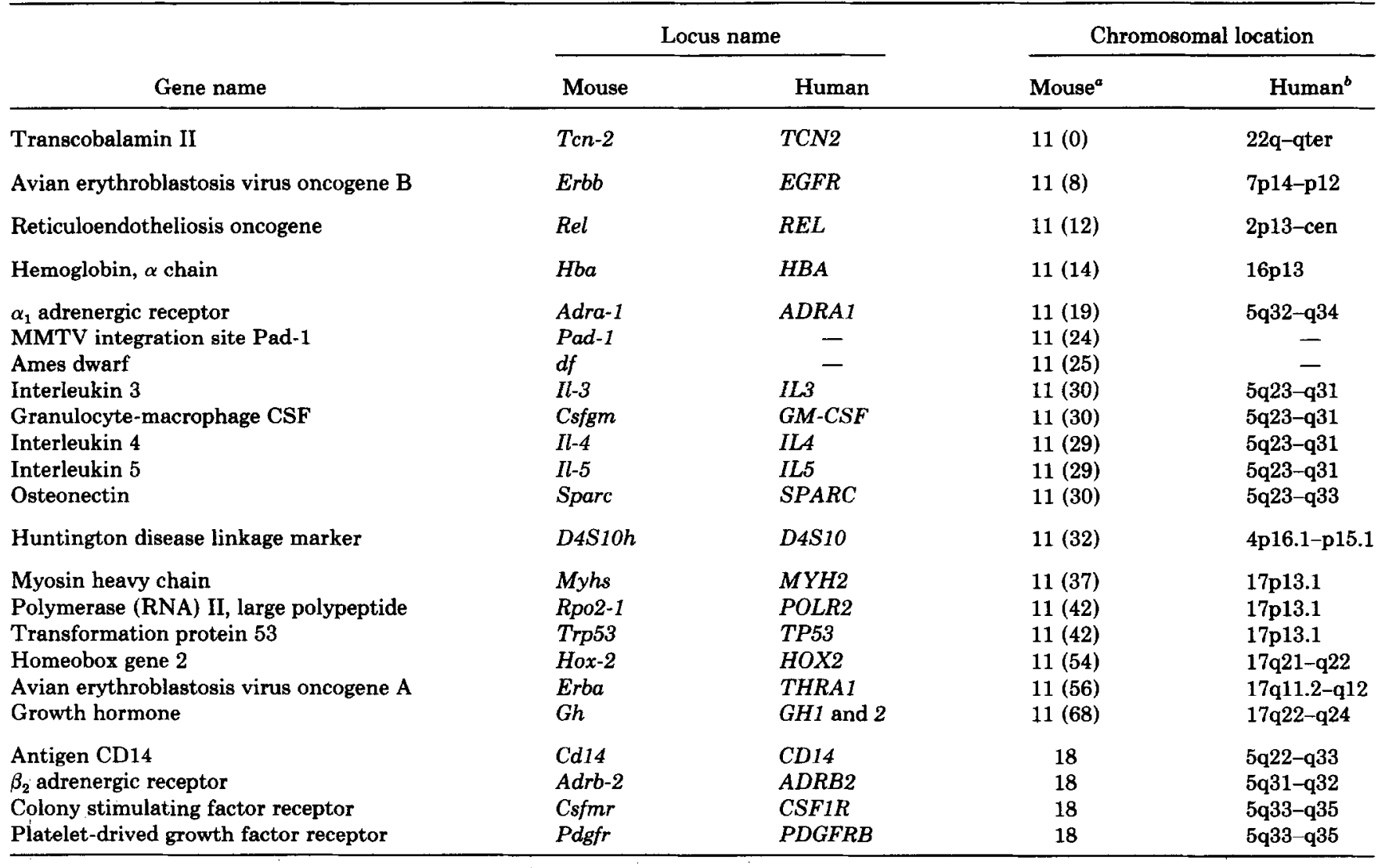

a The location of genes on mouse chromosome 11 is reported in $\mathrm{cM}$ (in parentheses) from the centromere anchor locus Tcn-2 according to the Jackson Laboratory (GBASE) map. The location of genes assigned to mouse chromosome 18 is unknown.

${ }^{b}$ The location of human genes is given according to the bands to which they have been localized. Human chromosome 5 data is from the Human Genome database as of October 26, 1990. Human chromosome 17 data is from Solomon and Barker (50).

The pituitary-specific transcription factor locus, Pit-1, maps to mouse Chr 16 and is mutated in the Snell dwarf (dw) (Camper et al., 1990; Li et al., 1990). Mapping of the $d f$ gene has ruled out several other homeotic genes as candidates based on their chromosomal locations. Hox-2 maps on Chr 11 to a position distal to $d f$ (Fig. 5), and the other homeobox gene clusters have been mapped to mouse $\mathrm{Chr} 2,5,6,14$, and 15. Pit-1 is the only pituitary-specific transcription factor that has been cloned, although lactotroph and thyrotroph specific factors have been described (Castrillo et al., 1989; Alexander et al., 1989). This backcross will be an invaluable resource for screening candidate genes, including other pituitary transcription factors, for linkage to $d f$.

\section{Loci on Mouse Chr 11 Exhibit Synteny Conservation with Human Chr 5 and 17}

The conservation of synteny among loci on mouse Chr 11 and human Chr 17 has been well documented
(Buchberg et al., 1989). The extent of linkage conservation makes it is generally possible to predict the location of genes on mouse Chr 11 from their map positions on human Chr 17. The large subunit of RNA polymerase II, Rpo2-1, had previously been assigned to mouse. Chr 11 with somatic cell hybrids (Pravtcheva et al., 1986). The human gene, POLR2, maps to 17p13.1 (Solomon and Barkèr, 1989). Thus, our localization of Rpo2-1 $2.3 \mathrm{cM}$ distal to $M y h s$ on mouse $\mathrm{Chr}$ 11 is consistent with expectations based on synteny conservation. We localized $E d p-1$ to the region just distal to Rpo2-1 and Asgr-1, consistent with preliminary data mapping EDPI to human Chr 17 by analysis of somatic cell hybrids (Wolf and Dixit, personal communication). The localization of $R p o 2-1$ and $E d p-1$ further extend the remarkable evolutionary conservation of human $\mathrm{Chr} 17$ and mouse $\mathrm{Chr} 11$ (Table 2).

Asgr-1 was first mapped on Chr 11 using RI strains (Sanford et al., 1988). We place Asgr-1 very close to the large subunit of RNA polymerase II ( 0 recombi- 
nants in 117 backcross progeny), consistent with a report showing linkage of $A s g r-1$ to Evi-2 in RI lines (Malo et al., 1990) (Fig. 5). We predict that the human asialoglycoprotein receptor gene is located on 17p13.1, close to POLR2.

Previous to this study, it was known that the $I l-3$, Il-4, Il-5, Csfgm, and Sparc loci mapped to mouse Chr 11 and human 5q23-q33. These genes are probably all in close proximity since $\mathrm{Il}-3$ and $C \mathrm{sfgm}$ are only $9 \mathrm{~kb}$ apart (Yang et al., 1988), $I l-4$ and $I l-5$ are only $90-240$ $\mathrm{kb}$ apart, and these two clusters may be within $500 \mathrm{~kb}$ of each other (van Leeuwen et al., 1989). A number of other genes which are localized to the same area of human $\mathrm{Chr} 5$, including platelet-derived growth factor receptor and a monocyte cell surface differentiation antigen antigen (CD14), have been mapped to mouse Chr 18 (Table 2). Thus, the extent of synteny conservation between human $\mathrm{Chr} 5$ and mouse $\mathrm{Chr} 11$ was unclear. We localized the $\alpha_{1}$ adrenergic receptor gene (Adra-1) on mouse $\mathrm{Chr} 11,9 \mathrm{cM}$ proximal to the Il-3/Csfgm cluster. Because $\alpha_{1}$ is on human $5 \mathrm{q} 32-\mathrm{q} 34$, the region of conserved synteny may be much more extensive than previously realized. More mapping studies are required to determine whether the entire 9 cM region between Adra- 1 and Il-3/Csfgm is homologous with human $\mathrm{Chr} 5$. Unfortunately, the location of Pad-1 in humans could not be determined due to lack of hybridization of this mouse probe to human DNA (data not shown). The localization of $d f$ between $A d r a-1$ and $I l-3 / C s f g m$ suggests that a human counterpart of $d f$ may be found on human Chr 5 .

\section{Conclusion}

This is the first comprehensive genetic analysis of the Ames dwarf mutation. The $d f$ gene has been mapped between the molecular markers Pad-1 and the Sparc/Il-3/Csfgm gene cluster using an intersubspecific backcross segregating $d f$. This large backcross of approximately 500 animals is a valuable resource for screening potential candidate genes for $d f$. The closest marker to $d f$ is $P a d-1$, where only 1 recombinant was observed in 117 individuals examined $(0.85$ $\pm 0.85 \mathrm{cM}$ ). Using a $95 \%$ confidence interval, the maximum distance to $d f$ from the closest proximal and distal molecular markers is 4.0 and $5.4 \mathrm{cM}$, respectively. In all likelihood, Pad-1 is sufficiently close to $d f$ to permit positional cloning using sequence-taggedsites as described (Green and Olson, 1990).

\section{ACKNOWLEDGMENTS}

This work was supported by a Basil O'Connor March of Dimes Starter Scholar Award (5-718; S.A.C.), the Michigan Memorial Phoenix Project (5550; S.A.C.), the University of Michigan Horace H. Rackham School of Graduate Studies (M.S.B., S.A.C.), the National Science Foundation (DCB 9004449; S.A.C.), the American
Cancer Society (CD62872; S.A.C.) the Cellular and Molecular Biology Training Grant (PHS T32-GM07315; R.W.K.), and the National Institutes of General Medical Sciences Medical Scientist Training Program (T32 GM07863; M.S.B.). We are indebted to Dr. A. Bartke for generously providing DF/B- $d f /+$ mating pairs, numerous DF/B- $d f / d f$ animals, and excellent advice on pituitary grafts and animal husbandry. We are especially grateful to Ms. L. Scarlett for her contributions to this work, including the maintenance of our DF/B colony and preparation of numerous plasmid DNAs. We thank the National Hormone Pituitary Program, University of Maryland (Baltimore, MD) for providing ovine growth hormone and Dr. A. Sonnenberg, Dr. R. Koenig, Dr. W. Paul, Dr. F. Rottman, Dr. M. Bartolomei, Dr. M. Young, Dr. V. Dixit, and Dr. J. Sanford for providing probes. We also thank Dr. R. Elliott for sharing data prior to publication, Dr. R. Reeves and Dr. M. Boehnke for helpful suggestions, and Dr. A. Buchberg and Dr. N. Copeland for providing probes and sharing data prior to publication. We acknowledge and appreciate the contributions of Dr. T. Saunders, Ms. I. Karolyi, and Mr. J. Lai to this work and thank Dr. M. Meisler and Dr. A. Bartke for reviewing the manuscript.

\section{REFERENCES}

1. Alexander, L. M., Gordon, D. F., Wood, W. M., KaO, M. Y., Ridgway, E. C., AND GuTierRez-HartmanN, A. (1989). Identification of thyrotroph-specific factors and cisacting sequences of the murine thyrotrophin $\beta$ subunit gene. Mol. Endocrinol. 3: 1037-1045.

2. Avner, P., Amar, L., Dandolo, L., AND Guenet, J. L. (1988). Genetic analysis of the mouse using interspecific crosses. Trends Genet. 4: 18-23.

3. BartKe, A. (1965a). Mouse Newslett. 32: 52-54.

4. BARTKE, A. (1965b). The response of two types of dwarf mice to growth hormone, thyrotropin, and thyroxine. Gen. Comp. Endocrinol. 5: 418-426.

5. BARTKE, A. (1979). Genetic models in the study of anterior pituitary hormones. In "Genetic Variation in Hormone Systems" (J. G. M. Shire, Ed.), Vol. I, CRC, Boca Raton, FL.

6. Bodner, M., Castrillo, J.-L., Theill, L. E., Deerink, T., Ellisman, M., AND KarIN, M. (1988). The pituitary-specific transcription factor GHF-1 is a homeobox-containing protein. Cell 55: 505-518.

7. Bonhomme, F., Catalan, J., BRitton-Davidian, J., ChapMaN, V., Moriwaki, K., Nevo, E., AND Thaler, L. (1984). Biochemical Diversity and Evolution in the genus Mus. Biochem. Genet. 22: 275-303.

8. Buchberg, A. M., Brownell, E., Nagata, S., Jenkins, N. A., AND CoPELAND, N. G. (1989). A comprehensive genetic map of murine chromosome 11 reveals extensive linkage conservation between mouse and human. Genetics 122: 153-161.

9. CAMPFr, S. A., Sainntirs, T. I., Katz, R. W., AND Refres, R. H. (1990). The Pit-1 transcription factor gene is a candidate for the Snell dwarf mutation. Genomics 8: 586-590.

10. CAstrillo, J.-L., BODNER, M., AND KARIN, M. (1989). Purification of growth hormone-specific transcription factor GHF1 containing homeobox. Science 243: 814-817.

11. CatTanach, B. M., AND KIRK, M. (1985). Differential activity of maternally and paternally derived chromosome regions in mice. Nature 315: 496-498.

12. Charlton, H.M., Clark, R. G., Robinson, I. C. A. F., Porter GoFf, A. E., Bugnon, C., AND BLOCH, B. A. (1988). Growth hormone-deficient dwarfism in the rat: A new mutation. J. Endocrinol. 119: 51-58.

13. Cheng, T. C., Beamer, W. G., Phillitss, J. A. III, Bartke, 
A., Mallonee, R. L., AND Dowling, C. (1983). Etiology of growth hormone deficiency in Little, Ames, and Snell dwarf mice. Enducrinology 113: 1669-1678.

14. Cotecchia, S., Schwinn, D. A., Randall, R. R., LeFkoWITZ. R. J., CARON, M. G., AND KoBILKA, B. K. (1988). Molecular cloning and expression of the cDNA for the hamster $\alpha_{1}{ }^{-}$ adrenergic receptor. Proc. Natl. Acad. Sci. USA 85: 71597163.

15. Eicher, E. M., AND BeAmer, W. G. (1980). New mouse dw allele: Genetic location and effects on lifespan and growth hormone levels. J. Hered. 71: 187-190.

16. Eicher, E. M., AND LeE, B. K. (1990). The NXSM recombinant inbred strains of mice: Genetic profile for 58 loci including the Mtv proviral loci. Genetics 125: 431-446.

17. ElliotT, R. W., LEe, B. K., AND EicheR, E. M. (1990). Localization of the growth hormone gene to the distal half of mouse chromosome 11. Genomics 8: 591-594.

18. Feinberg, A. P., ANd Vogelstein, B. (1982). A technique for radiolabeling DNA restriction endonuclease fragments to high specific activity. Anal. Biochem. 132: 6-13.

19. Fung, M. C., HAPEL, A. J., YMer, S., Cohen, D. R., JohnSON, R. M., CAMPBELL, H. D., AND YounG, I. G. (1984). Molecular cloning of cDNA for murine interleukin-3. Nature 307: 233-237.

20. Gough, N. M., Metcalf, D., Gough, J., Grail, D., and DuNN, A. R. (1985). Structure and expression of the mRNA for murine granulocyte-macrophage colony stimulating factor. $E M B O$ J. 4: 645-653.

21. Green, E. D., AND OLson, M. V. (1990). Chromosomal region of the cystic fibrosis gene in yeast artifical chromosomes: A model for human genome mapping. Science 250: 94-98.

22. Hodin, R. A., Lazar, M. A., Wintman, B. I., Darling, D. S., KOENIG, R. I., I ARSEN, P. R., MOORE, D. D., AND ChIN, W. W. (1989). Identification of a thyroid hormone receptor that is pituitary-specific. Science 244: 76-79.

23. Holland, P. W., Harper, S. J., MCVey, J. H., and Hogan, B. L. (1987). In vivo expression of mRNA for the $\mathrm{Ca}^{++}$-binding protein SPARC (osteonectin) revealed by in situ hybridization. J. Cell Biol. 105: 473-482.

24. Ingraham, H. A., Chen, R., Mangalam, H. J., Elsholtz, H. P., Flynn, S. E., Lin, C. R., Simmons, D. M., Swanson, L., AND RosENFELD, M. G. (1988). A tissue-specific transcription factor containing a homeodomain specifies a pituitary phenotype. Cell 55: 519-529.

25. Jackson-Grusby, L. L., Pravtcheva, D., Ruddle, F. H., AND LINZER, D. I. H. (1988). Chromosomal mapping of the prolactin/growth hormone gene in the mouse. Endocrinology 122: $2462-2466$.

26. Krug, M. S., AND Berger, S. L. (1987). First-strand cDNA synthesis primed with oligo d(T). "Methods in Enzymology" (S. L. Berger and A. R. Kimmel, Eds.), Vol. 152, pp. 316-325, Academic Press, San Diego.

27. Lazar, M. A., Hodin, R. A., Darling, D. S., and Chin, W. W. (1988). Identification of a rat c-erbA $\alpha$-related protein which binds deoxyribonucleic acid but does not bind thyroid hormone. Mol. Endocrinol. 2: 893-901.

28. Li, S., Crenshaw, E. B., III, Rawson, E. J., Simmons, D. M., Swanson, L. W., AND RosenfEID, M. G. (1990). Dwarf locus mutants lacking three pituitary cell types result from mutations in the POU-domain gene pit-1. Nature 347: 528-533.

29. Lieberman, M. E., Slabaugh, M. B., Rutledge, J. J., and GoRsKI, J. (1983). The role of estrogen in the differentiation of prolactin producing cells. $J$. Steroid Biochem. 19: 275-281.

30. Linzer, D. I. H., and Talamantes, F. (1985). Nucleotide sequence of mouse prolactin and growth hormone mRNAs and expression of these mRNAs during pregnancy. J. Biol. Chem. 260: 9574-9579.

31. Malo, D., Schurr, E., Levenson, R., AND Gros, P. (1990). Assignment of Na,K-ATPase $\beta_{2}$-subunit gene (Atpb-2) to mouse chromosome 11. Genomics 6: 697-699.

32. Mangalam, H. J., AlberT, V. R., IngRahaM, H. A., KaPIloff, M., Wilson, L., Nelson, C., Elsholtz, H., and RoSENFELD, M. G. (1989). A pituitary POU domain protein, Pit1 , activates both growth hormone and prolactin promoters transcriptionally. Genes Dev. 3: 946-958.

33. McKusick, V. A. (1989). Mapping the genes for hormones and growth factors and the mutations causing disorders of growth. Growth Genet. Horm. 5: 1-10.

34. Naylor, S. L., Chin, W. W., Goodman, H. M., Lalley, P. A., Grzeschik, K. H., AND SaKaJuchi, A. V. (1983). Chromosome assignment of genes encoding the $\alpha$ and $\beta$ subunits of glycoprotein hormones in man and mouse. Somatic Cell Genet. 9: 757-770.

35. O'Hara, B. F., Bendotti, C., Reeves, R. H., Oster-GranITE, M. L., Coyle, J. T., AND GearharT, J. D. (1988). Genetic mapping and analysis of somatostatin expression in Snell dwarf mice. Mol. Brain Res. 4: 283-292.

36. Phillips, J. A., III, Beamer, W. G., AND BartKe, A. (1982). Analysis of growth hormone genes in mice with genetic defects of growth hormone expression. J. Endocrinol. 92: 405407.

37. PHILlIPS, J. A., III (1985). Genetic diagnosis: Differentiating growth disorders. Hosp. Pract. 20: 85-114.

38. Pravtcheva, D., Rabin, M., Bartolomei, M., Corden, J., AND RUDDLE, F. H. (1986). Chromosomal assignment of gene encoding the largest subunit of RNA polymerase II in the mouse. Sumalic Cell Mol. Genet. 12: 523-528.

39. Rimoin, D. L., AND Schimke, R. L. (1971). "Genetic Disorders of the Endocrine Glands," C.V. Mosby, St. Louis.

40. Robert, B., Barton, P., Minty, A., Daubas, P., Weydert, A., Bonhomme, F., Catalan, J., Chazottes, D. Guenet, J. L., AND BUCKINGHAM, M. (1985). Investigation of genetic linkage between myosin and actin genes using an interspecific mouse back-cross. Nature 314: 181-183.

41. Roux, M., Bartke, A., Dumont, F., and Dubois, M. P. (1982). Immunohistological study of the anterior pituitary gland-pars distalis and pars intermedia-in dwarf mice. Cell Tissue Res. 223: 415-420.

42. Rugh, R. (1990). "The Mouse: Its Reproduction and Development," p.5, Oxford Univ. Press, Oxford Univ. Press, Oxford.

43. SaIki, R. K., Gelfand, D. H., Stoffel, S., ScharF, S. J., Higuchi, R., Horn, G. T., Mullis, K. B., AND ERlich, H. A. (1988). Primer-directed enzymatic amplification of DNA with a thermostable DNA polymerase. Science 239: 487-491.

44. Sambrook, J., Fritsch, E. F., and Maniatis, T. (1989). "Molecular Cloning: A Laboratory Manual," Cold Spring Harbor Laboratory Press, Cold Spring Harbor, NY.

45. SANFord, J. P., ElliotT, R. W., AND Doyle, D. (1988). Asialoglycoprotein receptor genes are linked on chromosome 11 in the mouse. DNA 7: 721-728.

46. Schatble, R., AND Gowen, J. W. (1961). A new dwarf mouse. Genetics 46: 896.

47. Simmons, D. M., Voss, J. W., Ingraham, H. A., Holloway, J. M., Broide, R. S., Rosenfeld, M. G., and Swanson, L. W. (1990). Pituitary cell phenotypes involve cell-specific Pit1 mRNA translation and synergistic interactions with other clusses of transcription factors. Genes Dev. 4: 695-711. 
48. Slabaugh, M. B., Hoffman, L. E., Lieberman, M. E., RutLEDGE, J. J., AND GORSKI, J. (1982). Genomic organization of prolactin and growth hormone coding sequences in dwarf and normal mice. Mol. Cell. Endocrinol. 28: 289-297.

49. Soares, M. J., Bartke, A., Colosi, P., and Talamantes, F. (1984). Identification of a placental lactogen in pregnant Snell and Ames dwarf mice. Proc. Soc. Exp. Biol. Med. 175: 106-108.

50. SOLOMON, E., AND BARKER, D. F. (1989). Report of the committee on the genetic constitution of chromosome 17. Cytogenet. Cell Genet. 51 : 319-337.

51. Takeuchi, T., Suzuki, H., Sakural, S., Nogami, H., OKUMA, S., AND IsHIKAWA, H. (1990). Molecular mechanism of growth hormone (GH) deficiency in the spontaneous dwarf rat: Detection of abnormal splicing of GH messenger ribonucleic acid by the polymerase chain reaction. Endocrinology 126: 31-38.

52. Ullrich, A., Coussens, I., HaYflick, J. S., Dull, T. J., Gray, A., TAM, A. W., LeE, J., Yarden, Y., LibermanN, T. A., Schlessinger, J., Downward, J., MaYes, E. L. V., Whittle, N., Waterfield, M. D., and Seeburg, P. $H$. (1984). Human epidermal growth factor receptor cDNA sequence and aberrant expression of the amplified gene in A431 epidermoid carcinoma cells. Nature 309: 418-425.

53. van Leeuwen, B. H., Martinson, M. E., WebB, G. C., AND
YouNG, I. G. (1989). Molecular organization of the cytokine gene cluster, involving the human IL-3, IL-4, IL-5 and GMCSF genes, on human chromosome 5. Blood 73: 1142-1148.

54. Weydert, A., Daubas, P., Caravatti, M., Minty, A., BuGAISKy, G., CoHEN, A., Robert, B., AND BuckinghaM, M. (1983). Sequential accumulation of mRNAs encoding different myosin heavy chain isoforms during skeletal muscle development in vivo detected with a recombinant plasmid identified as coding for an adult fast myosin heavy chain from mouse skeletal muscle. J. Biol. Chem. 258: 13,867-13,874.

55. Weydert, A., Daubas, P., Lazaridis, I., Barton, P., Garner, I., Leader, D. P., Bonhomme, F., Catalan, J., SiMON, D., Guenet, J. L., Gros, F., AND Buckingham, M. E. (1985). Genes for skeletal muscle myosin heavy chains are clustered and not located on the same mouse chromosome as a cardiac myosin heavy chain gene. Proc. Natl. Acad. Sci. USA 82: 7183-7187.

56. WoYchiK, R. P., CAMPER, S. A., Lyons, R. H., Horowitz, S., Goodwin, E. C., AND RotTman, F. M. (1982). Cloning and nucleotide sequencing of the bovine growth hormone gene. Nucleic Acids Res. 10: 7197-7210.

57. Yang, Y.-C., Kovacic, S., Kriz, R., Wolf, S., Clark, S. C., Wellems, T. E., Nienhuis, A., AND EPSTEIN, N. (1988). The human genes for GM-CSF and IL 3 are closely linked in tandem on chromosome 5. Blood 71: 958-961. 